\title{
Life history and instream distribution of the endangered estuarine goby Acanthogobius insularis from Okinawa-jima Island, Japan
}

\author{
TAIGA KUNISHIMA ${ }^{1}$, RISA IWAMOTO ${ }^{2}$, MIDORI IIDA ${ }^{3,4}$ AND KATSUNORI TACHIHARA ${ }^{2}$ \\ ${ }^{1}$ Graduate School of Engineering and Science, University of the Ryukyus, 1 Senbaru, Nishihara, Okinawa 903-0213, Japan, ${ }^{2}$ Faculty \\ of Science, University of the Ryukyus, 1 Senbaru, Nishihara, Okinawa 903-0213, Japan, ${ }^{3}$ Tropical Biosphere Research Center, \\ University of the Ryukyus, 1 Senbaru, Nishihara, Okinawa 903-0213, Japan, ${ }^{4}$ Sado Marine Biological Station, Faculty of Science, \\ Niigata University, 87 Tassha, Sado, Niigata 952-2135, Japan
}

\begin{abstract}
The genus Acanthogobius of gobiioid fish has been reported for six species from East Asia, and inhabits estuarine and coastal waters. Within this genus, Acanthogobius insularis is an endangered and endemic goby in the Amami-oshima and Okinawa-jima Islands, southern Japan, and its range is restricted to the lowermost course of a few river basins. Basic knowledge on this species is scarce in spite of its vulnerable conservation status. The purpose of this study was to elucidate the life history of A. insularis. Monthly sampling was conducted at five stations in the Taiho River, Okinawa-jima Island, from November 2014 to November 2015. Monthly standard length (SL) distributions were unimodal except in April during the recruiting period, suggesting that A. insularis is an annual species. Analysis of the gonadosomatic index and histological observations of the ovaries revealed that this species spawns from January to May. The beginning of the spawning season seems to be related to a decline in water temperature in December. Growth rates appeared to be lower from April to December and higher in winter months. From monthly collections, A. insularis was found to move upstream with growth, and gather at spawning grounds during the reproductive season. Acanthogobius insularis might be threatened by increasing water temperature due to climate change, since low water temperatures appear to be important for their reproduction and growth. Moreover, habitat diversity, from tidal flats for recruiting grounds to upstream sites with cobbles for spawning, is needed to complete their life cycle, and should be conserved.
\end{abstract}

Keywords: life history, habitat shift, instream distribution, estuary, tidal flat, endemic species, endangered species, conservation, genus Acanthogobius

Submitted 16 October 2017; accepted 15 December 2017; first published online 4 March 2018

\section{INTRDDUCTION}

Estuary and coastal areas are important habitats as nurseries and feeding grounds for various kinds of fishes, for both resident species and temporal or migratory species that move between rivers and oceans, such as diadromous fishes (Elliot \& Dewailly, 1995; Meager et al., 2005; Elliot et al., 2007; Whitfield, 2016). Estuaries have the important function of providing numerous habitats for fish and links between rivers and ocean areas (Able, 2005). Conversely, human activities, such as reclamation for aquaculture, agriculture, and construction of artificial structures, have negatively affected estuarine and river ecosystems and their associated biodiversity (Arun, 2005; Eriksson et al., 2010). In general, rivers in islands are shorter and narrower than those on continents, and so it is likely that they are strongly affected by human activities.

The Ryukyu Archipelago is composed of 198 islands, is $\sim 1000-\mathrm{km}$ long, and is located in sub-tropical and tropical

Corresponding author:

T. Kunishima

Email: taigakunishima@gmail.com areas of southern Japan. In the archipelago, sediment pollution by laterite red soil run-off from the land due to road and dam construction has a key issue for the conservation of water ecosystems (Fujii, 2001).

Brackish areas are inhabited by various fish species and the suborder Gobioidei is a representative fish in these areas (Humphries \& Potter, 1993; Yokoo et al., 2012). The benthic gobioid fish genus Acanthogobius is mainly distributed in East Asia, and inhabits estuarine and coastal waters (Suzuki et al., 2004). Acanthogobius luridus and A. elongates are distributed in the north-west Pacific: Korean and Chinese coasts of Bohai Sea, Yellow Sea and East China Sea (Froese \& Pauly, 2017). Four species of this genus, A. flavimanus, A. lactipes, A. hasta and A. insularis, have been recorded in Japan (Akihito et al., 2013). Acanthogobius flavimanus and A. lactipes are widely distributed and one of the most common gobies found in the estuaries of mainland Japan (Takizawa, 1994; Zama, 1999; Kanou et al., 2000; Okazaki et al., 2012). Conversely, A. insularis is an endemic species that is distributed only in the Amami-oshima and Okinawa-jima Islands of the Ryukyu Archipelago. This species is registered as 'Vulnerable (VU)' in the Red Data Books of the Ministry of the Environment of Japan, and Kagoshima and Okinawa Prefectures, and is threatened with extinction (Tachihara, 
2005, 2015; Yonezawa \& Shinomiya, 2016). Although this species has been recognized as a single species with A. lactipes, inhabiting mainland Japan for many years, it was described as a new species by Shibukawa \& Taki (1996). The spawning season of $A$. insularis has been reported based on the presence of mature females in the Taiho River in Okinawa-jima Island (Shibukawa \& Taki, 1996). However, no study has focused on the reproduction of $A$. insularis in detail. Furthermore, little is known about their life-history traits, such as lifespan and growth. The habitat of $A$. insularis is strictly limited to brackish areas in several rivers in Okinawa-jima Island (Shibukawa \& Taki, 1996). In addition, Tachihara (2015) noted that their populations may be decreasing due to environmental degradation following riverine and coastal developments, such as wetland drainage, resulting in increased turbidity and sedimentation, and decreased water flow. In the Taiho River, which is one of the main habitats of $A$. insularis and flows to the Shioya Bay in the Ogimi Village in the northern part of Okinawa-jima Island, the aquatic environment has been destroyed by red soil run-off from the land at $\sim 657$ tons per year owing to the construction of roads and the Taiho Dam (Okinawa Prefecture, 2013). Due to the narrow entrance of Shioya Bay, red soils have been continuously deposited at the bottom of the bay. Therefore, one of the main habitats of $A$. insularis in Okinawa-jima Island still faces severe threat. To conserve this species under such conditions, its life history and habitat use should be investigated in detail. The objective of this study was to obtain fundamental information on A. insularis by investigating its life history, such as growth, reproduction, senescence, and habitat use in Okinawa-jima Island.

\section{MATERIALS AND METHODS}

\section{Sampling sites}

The surveys were conducted in the Taiho River, Ogimi Village, northern Okinawa-jima Island in southern Japan. The river is about $10.3-\mathrm{km}$ long and has an estuary that flows into Shioya Bay. The Taiho Dam was constructed in the upper reaches, $2.9 \mathrm{~km}$ from the entrance of Shioya Bay. Five stations were set in the brackish area along the river (Figure 1; Stations A-E). Features of each station were as follows. Station A was located on an open mud flat in the estuary. The substrate was soft mud without dead coral, debris, or sea algae, and there were bivalves, including shells of Anadara antiquata and living Isognomon ephippium. Station B had a muddy substrate with cobble flowing from the river. Filamentous algae flourished in winter. An artificial waterway was constructed in the vicinity, and a revetment was reconstructed throughout the study period. Mangroves such as Kandelia obovata and Bruguiera gymnorrhiza grew near Station C, which had a similar substrate to Station B, and filamentous algae also flourished in winter. A small tributary flowed into the Taiho River near Station C. Cobbles ( $\sim 15 \mathrm{~cm}$ in diameter) were dotted on the pebble substrate at Station D. The substrate of Station E was finer than that of Station D.

\section{Fish collection and environmental measurement}

Acanthogobius insularis individuals were collected using a small seine net with a sinker attached to reach the bottom during the daytime (1.0-mm mesh; $0.8 \mathrm{~m}$ in height; $3.5 \mathrm{~m}$ in width; with a bag 1.0-m long and $0.7-\mathrm{m}$ diameter; Supplementary Material 1). Sampling was performed at each station monthly from November 2014 to November 2015. The seine net was hauled by two people using poles set at each end of the net along the shoreline during the low tides of spring tides during the daytime. At each station, the net was hauled once for $5.0 \mathrm{~m}$ to minimize the impact of sampling on the population. Additional samplings were conducted using a hand net when the body size ranges of monthly samples became biased due to low sample sizes. Water temperature to the nearest $0.1^{\circ} \mathrm{C}$ and salinity (S; UNESCO, 1981) were measured at each sampling using a mercury thermometer and a refractometer (S/Mill-E or PAL-06S, ATAGO), respectively.

Since A. insularis is registered as 'Vulnerable' (VU) in the Red Data Book by the Ministry of the Environment of Japan (Tachihara, 2015), a maximum of 25 individuals were randomly subsampled each month and taken to the laboratory. Other individuals in each station were placed in a container attached to a grid sheet (10-mm mesh) in the field (Supplementary Material 2), and a photograph was taken using a digital camera (Stylus TG-4, Olympus). Then, fish were released at each site after the number of individuals was determined. Subsampled individuals were euthanized using ice in the field and brought to the laboratory. Total length (TL) and standard length (SL) of collected specimens were measured to the nearest $0.1 \mathrm{~mm}$ using a digital calliper (Digimatic Calliper, Mitsutoyo) in the laboratory. TLs of released fish were estimated to the nearest $0.1 \mathrm{~mm}$ from images using the software Image J 1.48i (Schneider et al., 2012) and converted to SL by the following formula, generated based on the relationship between TL and SL in the samples: $\mathrm{TL}=0.8355 \times \mathrm{SL}+0.1363, R^{2}=0.9922, \mathrm{~N}=303$ (except for two specimens with a broken caudal fin).

\section{Gonadosomatic index and histological observation of ovary}

Body weight (BW) and gonad weight (GW) were measured to the nearest $0.001 \mathrm{~g}$ for each specimen. Sex was mainly determined by histological observation of the gonadal tissue during dissection. Moreover, the sex was determined by direct observations of the gonadal morphology during the spawning season (January to May, see details in the Results) as follows; ovary: rounded and yellowish; testes: folded and whitish. Individuals smaller than $13.9 \mathrm{~mm}$ were determined as sex-indistinct owing to undeveloped gonads. The spawning season was estimated based on monthly changes in the female gonadosomatic index (GSI), which was calculated as follows: $\mathrm{GSI}=(\mathrm{GW} / \mathrm{BW}-\mathrm{GW}) \times 100$, and based on histological observations of ovaries. However, GSI values of females caught between June and November were assumed to be zero, because GW could not be measured owing to nondeveloped gonads during this period. The gonads were fixed using $10 \%$ buffered formalin and dehydrated in paraffin. Thin sections of ovaries $(7 \mu \mathrm{m})$ were stained with Mayer's haematoxylin and eosin using routine histological procedures to examine the developmental stages of the oocytes in the ovary. The number of specimens used for histological analyses varied from one to 24 each month. Many individuals had no clear gonad during the non-spawning season; thus, the 


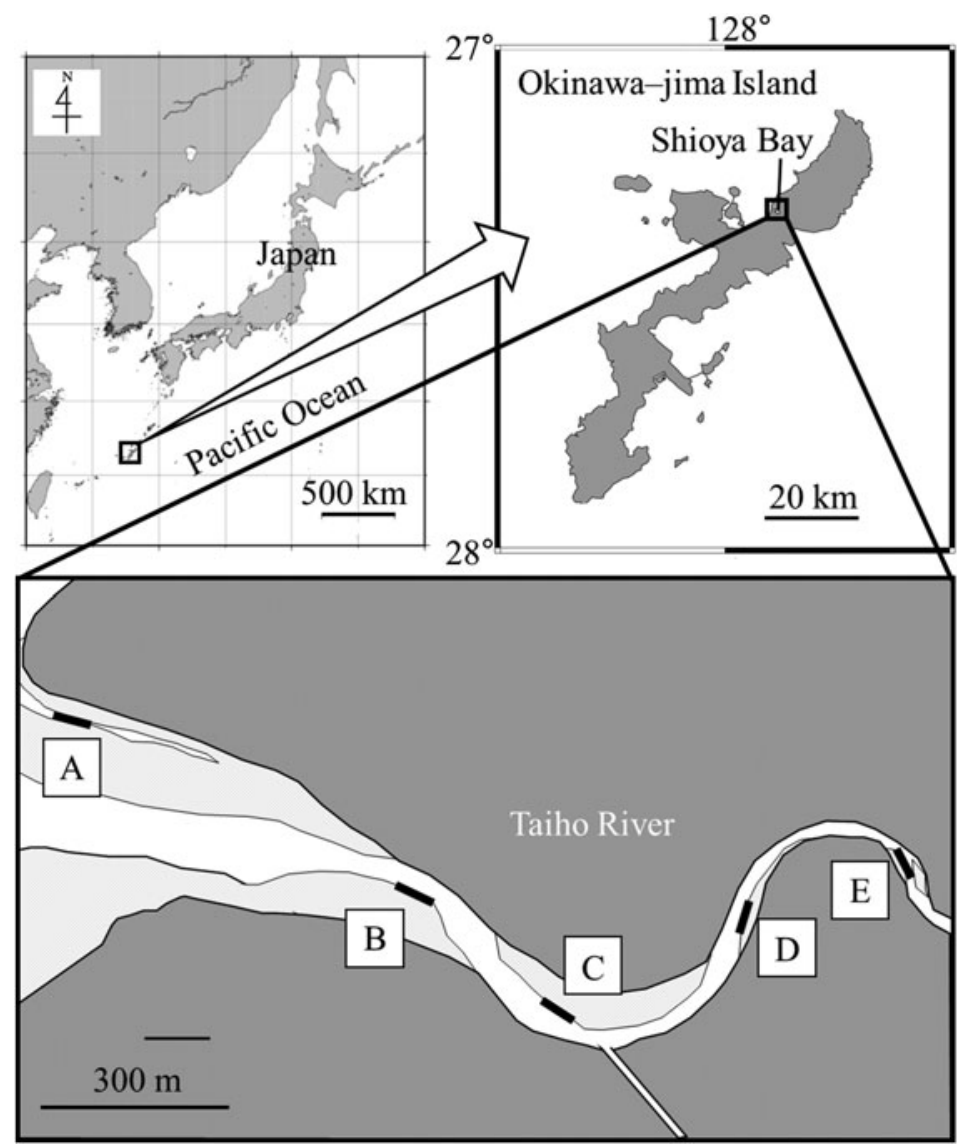

Fig. 1. Maps showing the study site at the Taiho River in Okinawa-jima Island, Japan. Black bars show sampling stations. Each colour shows the following; grey areas: land; light grey areas: sand or mud exposed at low tide; white areas: water at low tide.

number of samples during the non-spawning season was low $(\mathrm{N}=2-9)$. Oocyte stages were classified based on the methodology described by Kuno \& Takita (1997) and Kitano et al. (2003). In the present study, the mature stage of each individual was determined based on the most developed oocytes in the ovary. Sexually mature females were defined as having an ovary in the late development stage (tertiary yolk globule to maturation stage; see Results). Based on the morphological observations, individuals smaller than $10 \mathrm{~mm}$ SL were classified as juvenile (see details in the Results).

\section{Monthly growth}

As a preliminary study, age in days was estimated using the sagittal otolith. Otoliths were extracted from each specimen under a stereomicroscope, mounted on glass slides using clear nail varnish, and examined under an optical microscope (NIKON, ECLIPSE Ni-u). The rings were observed and assumed to have been deposited daily; two people counted the number of rings independently. Next, the hatching date of specimens was calculated based on sampling dates and estimated ages $(\mathrm{N}=166)$. However, the estimated ages differed largely between the two readers, and the hatching dates calculated did not match the spawning season (see Results), which was estimated from monthly GSI values and histological observations. Therefore, we concluded that the use of otoliths for age determination was not appropriate for A. insularis. Thus, we estimated their growth from monthly changes in the average SLs. As there were bimodal SL distributions in some months (see Results), the average for each cohort was calculated instead.

\section{Statistical analyses}

Differences in SL between males and females were analysed by Mann-Whitney U-test. Kruskal-Wallis test was used to compare SL among stations. When significant differences were determined by Kruskal-Wallis test, post-hoc multiple comparison tests were carried out using the Holm method. The sex ratio was tested by a Fisher's exact test. Significant differences were determined at the 0.05 probability level. All statistical analyses were conducted using $\mathrm{R}$ version 3.0.2 ( $\mathrm{R}$ Core Team, 2013).

\section{RESULTS}

\section{Water temperature and salinity}

The lowest mean water temperature recorded was $17.1^{\circ} \mathrm{C}$ in January 2015, following which it rapidly increased from March (Figure 2), reaching the highest mean temperature of $32.6^{\circ} \mathrm{C}$ in July before starting to decrease in August or September. When observed at each station, Station A had higher water temperatures than the other stations throughout the year (Table 1). Salinity was also higher in the lower stations (Stations A and B) than in stations in the upper reaches. 


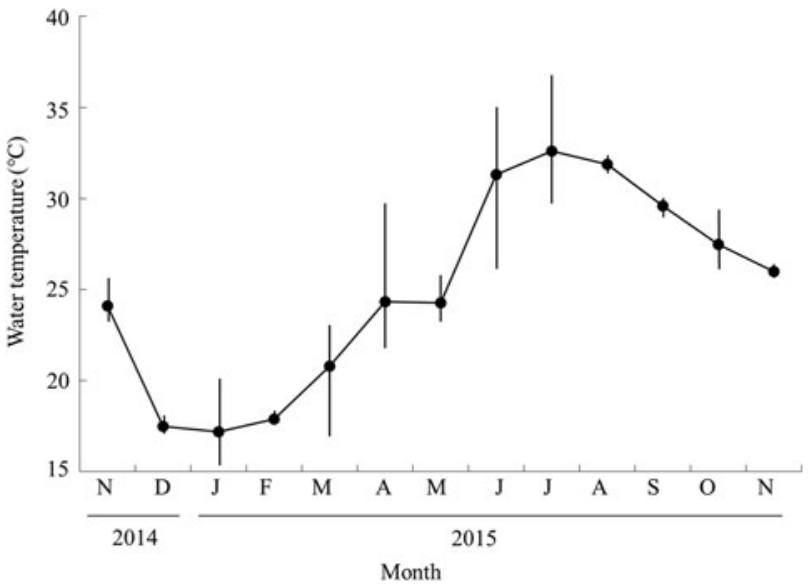

Fig. 2. Monthly changes in water temperature of the Taiho River in Okinawa-jima Island. Closed circles and bars show the average and standard deviation, respectively.

\section{Standard length ranges}

In total, 636 individuals were collected, among which 331 individuals were released in the field, and their SLs were estimated from photographs. Out of 305 individuals collected and brought to the laboratory, 271 and 34 were caught using the small seine net and hand net, respectively.

The SL of sampled individuals was 13.9-54.5 mm (mean \pm S.D.: $39.8 \pm 10.8 \mathrm{~mm}, \mathrm{~N}=115)$ for females, $19.7-46.4 \mathrm{~mm}$ $(30.5 \pm 7.2 \mathrm{~mm}, \mathrm{~N}=29)$ for males, and $9.6-52.2 \mathrm{~mm}$ $(25.9 \pm 8.4 \mathrm{~mm}, \mathrm{~N}=161)$ for sex-indistinct individuals, and $9.6-54.5 \mathrm{~mm}(24.4 \pm 10.4 \mathrm{~mm}, \mathrm{~N}=636)$ for all individuals including those released. Females were significantly larger than males (Mann-Whitney $U$-test, $U=2499.5, P<0.01$ ). The smallest individual had a SL of $9.6 \mathrm{~mm}$ and was considered a juvenile just after recruiting based on its body size and low amount of pigmented colouration. Juvenile A. insularis were distinguished from Favonigobius sp. using the number of spiny-rays on the first dorsal fin (8), which is a unique feature of this species. The SL frequency distribution of $A$. insularis collected by the seine and hand nets over 1 year showed clear monthly variation (Figure 3 ). Unimodal patterns were observed in all months except for April 2015, when juveniles smaller than $10 \mathrm{~mm}$ SL appeared. After May 2015, large individuals ( $\geq 40 \mathrm{~mm} \mathrm{SL}$ ) disappeared and remained absent until the end of the survey in November 2015. The average SL slowly but continuously increased from April to November. Monthly changes in the SL were greater from December onwards, and the mean SL increased to over $40 \mathrm{~mm}$ in January or February. Then, it increased slowly until March. Monthly

Table 1. Water temperature and salinity at each station at the Taiho River from November 2014 to November 2015.

\begin{tabular}{llllllll}
\hline & \multicolumn{3}{c}{ Temperature $\left({ }^{\circ} \mathrm{C}\right)$} & & \multicolumn{3}{c}{ Salinity (S) } \\
\cline { 2 - 5 } \cline { 7 - 8 } Station & Average & Highest & Lowest & & Average & Highest & Lowest \\
\hline $\mathrm{A}$ & 26.5 & 36.8 & 17.7 & 21.5 & 37.0 & 13.0 \\
$\mathrm{~B}$ & 25.1 & 32.3 & 17.4 & & 17.9 & 27.0 & 7.0 \\
$\mathrm{C}$ & 24.4 & 32.4 & 16.9 & & 12.7 & 22.0 & 3.0 \\
$\mathrm{D}$ & 23.8 & 32.5 & 17.0 & & 5.2 & 14.0 & 1.0 \\
$\mathrm{E}$ & 22.9 & 29.5 & 16.9 & & 3.1 & 5.0 & 2.0 \\
\hline
\end{tabular}

growth, which was estimated by the average SL in each month, was slow from April to November (up to $6.8 \mathrm{~mm} /$ month), following which it became rapid to about $10 \mathrm{~mm}$ per month between November and January (Figure 3).

\section{Reproduction}

Monthly variation in GSI for females was highest during the winter season (Figure 4). The average GSI of females began to increase in December (mean \pm S.D.: $0.8 \pm 0.9$ ), reaching a peak in March $(10.3 \pm 4.5)$, and rapidly decreasing in May $(1.0 \pm 2.5)$. Then, GSI values were almost zero from June to November 2015.

Histological observations of $A$. insularis ovaries revealed that maturity occurred in the following stages (Supplementary Material 3): peri-nucleus stage ( $\mathrm{PN}, \mathrm{N}=40$ ); yolk vesicle stage $(\mathrm{YV}, \mathrm{N}=2)$; primary yolk globule stage $(\mathrm{PY}, \mathrm{N}=3)$; secondary yolk globule stage ( $\mathrm{SY}, \mathrm{N}=6$ ); tertiary yolk globule stage ( $\mathrm{TY}, \mathrm{N}=55)$; migratory nucleus stage $(\mathrm{MN}, \mathrm{N}=5)$; and atretic stage $(\mathrm{AT}, \mathrm{N}=1)$. No post-ovulatory follicles (POF) were observed in this study. Moreover, as various stage oocytes were observed in one section of many individuals, oocyte development in $A$. insularis was asynchronous. Matured females from TY to MN were observed from January to May, and accounted for approximately $80 \%$ of individuals in March and April (Figure 4). Conversely, all females caught from June to December were immature. Results of GSI analysis and histological observations indicated that their spawning season occurs between January and May in the Taiho River, Okinawa-jima Island.

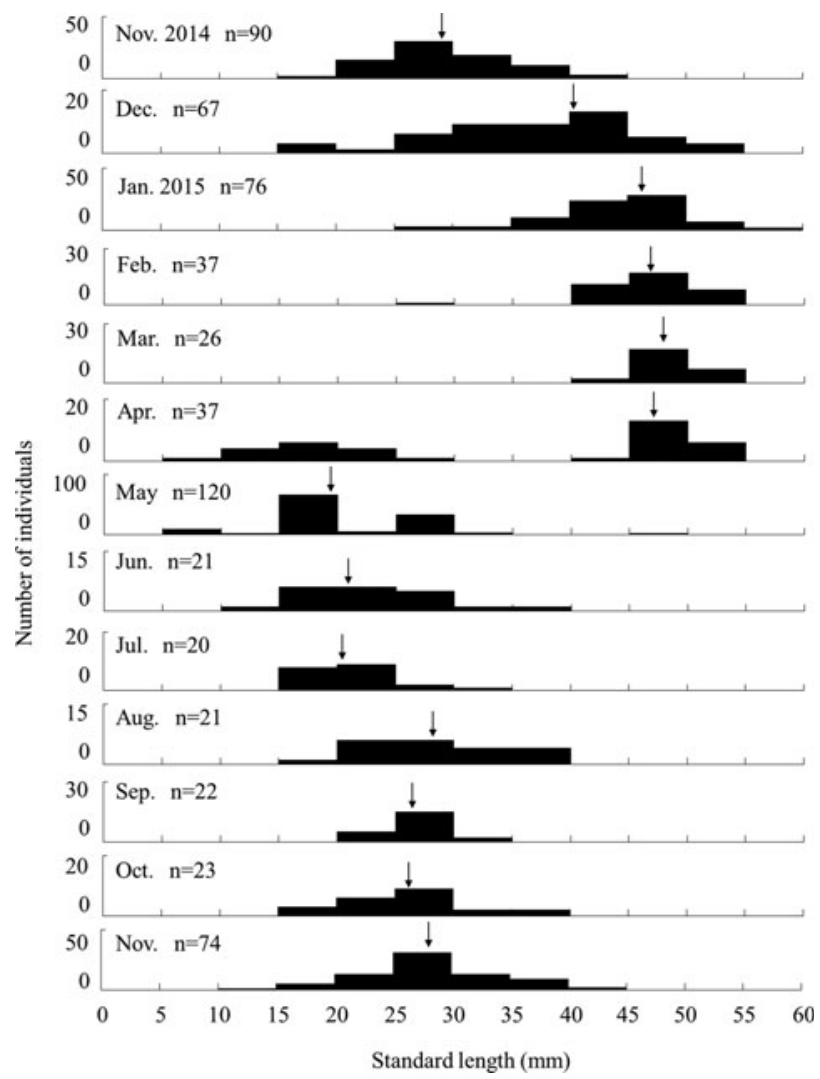

Fig. 3. Monthly changes in standard length frequency of Acanthogobius insularis with whole samples collected by seine and hand nets from the Taiho River, Okinawa-jima Island. Arrows show the average values of SL. 


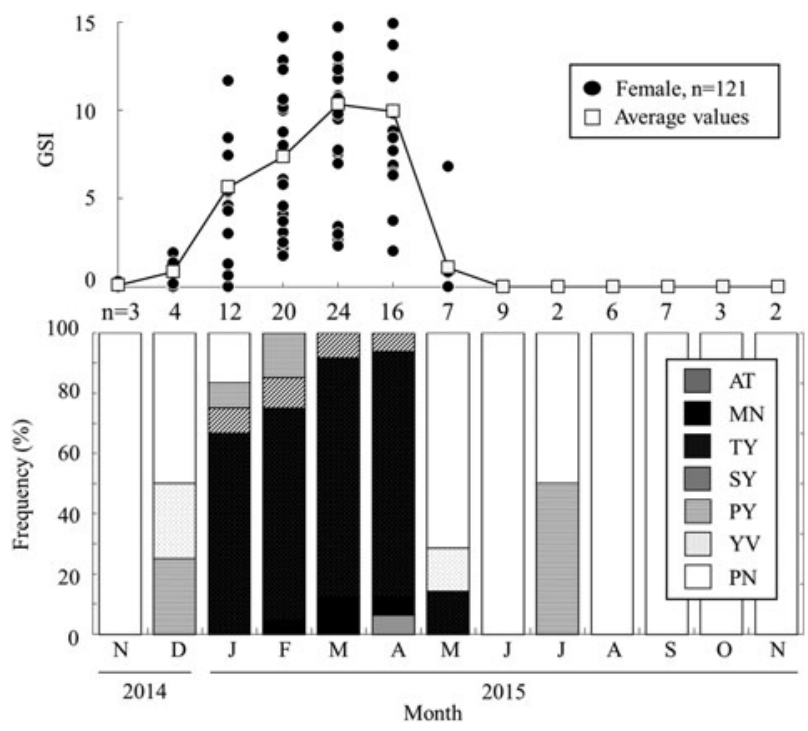

Fig. 4. Monthly changes in gonadosomatic index (above) and the frequency of various gonadal maturity stages (below) occurring in female Acanthogobius insularis collected at the Taiho River in Okinawa-jima Island. AT: atretic stage; MN: migratory stage; TY: tertiary yolk stage; SY: secondary yolk globule stage; PY: primary yolk globule stage; YV: yolk vesicle stage; PN: peri-nucleus stage.

The relationship between SL and GSI in females during the spawning season showed that the GSI values was greater in individuals over $40 \mathrm{~mm} \mathrm{SL}$, and the smallest mature female estimated by the histological observation was at $40.8 \mathrm{~mm} \mathrm{SL}$ with a GSI value of 3.0 (Figure 5). The lowest GSI value in a mature female based on the histological observation was 2.5, with a SL of $48.9 \mathrm{~mm}$.

\section{Instream distribution}

The SL of individuals collected by the small seine net each month varied among stations (Kruskal-Wallis test, $P<$ 0.05; Figure 6). The number of individuals was lower in Station A and higher in Stations C and D. Juveniles $(<10 \mathrm{~mm} \mathrm{SL})$ occurred at Stations B and C (Holm method, each $P<0.05)$. Large individuals $(\geq 40 \mathrm{~mm} \mathrm{SL})$ were abundant in the upper stations. The SL of individuals at Station D was significantly larger, and of Station A was smaller, than that at other stations.

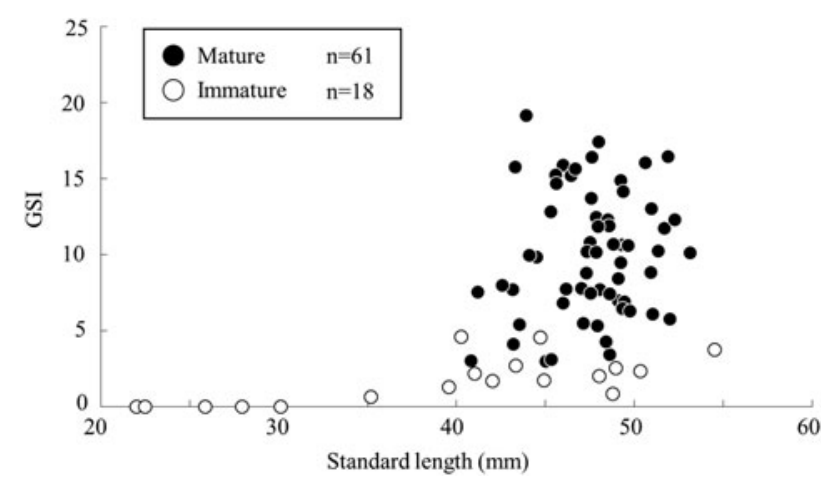

Fig. 5. Relationship between gonadosomatic index and standard length of female Acanthogobius insularis during the spawning season, collected at the Taiho River in Okinawa-jima Island.

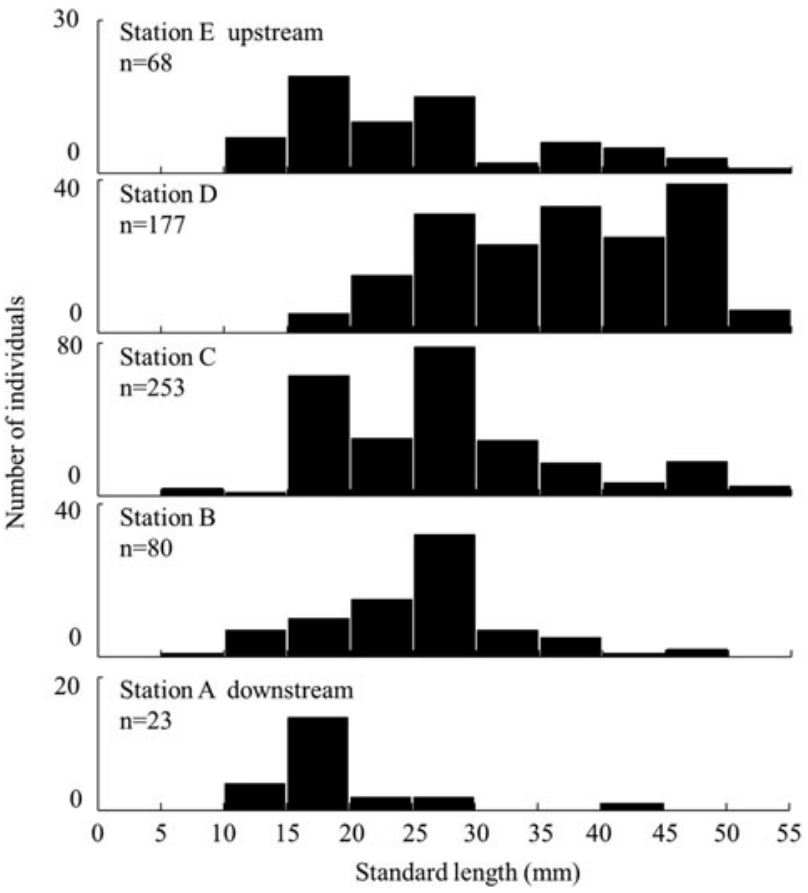

Fig. 6. Standard length distribution of Acanthogobius insularis collected by seine net at each station at the Taiho River in Okinawa-jima Island.

For the monthly changes in SL frequency at each station, small individuals, including juveniles, were widely distributed in the Taiho River during the non-spawning season from June to December (Figure 7 ). Larger individuals ( $\geq 40 \mathrm{~mm} \mathrm{SL}$ ), which were probably matured, according to their size, mainly appeared in the upper area of Stations C and D during the spawning season and were present at lower numbers in May.

\section{DISCUSSIDNS}

\section{Lifespan and growth}

The results of a yearlong survey of the endemic endangered goby $A$. insularis on the Okinawa-jima Island showed that this species is annual and exhibits rapid growth during the winter season. Based on monthly changes in length frequency distribution, A. insularis individuals were recruited as juveniles in April and May and grew to over $50 \mathrm{~mm} \mathrm{SL}$, with large individuals disappearing after May (Figure 3). Moreover, monthly SL frequency distributions were unimodal, except during their recruiting period in April. Therefore, we could conclude that this species is annual. Compared with congener species, although A. lactipes is also reported to be annual (Takizawa et al., 1994; Zama, 1999), the senescence of A. flavimanus and A. hasta is 1 or 2 years, and occasionally 3 years for A. flavimanus (Miyazaki, 1940; Hoshino et al., 1993; Kuno \& Takita, 1997; Zama, 1999; Nakamura, 2002). Acanthogobius insularis individuals have a relatively short life cycle compared with other species in the genus.

Monthly growth was slow from April to November, and rapid from November to January (Figure 3). Recruitment occurred only in April and May suggesting the slow growth during April to November was not caused by underestimation 


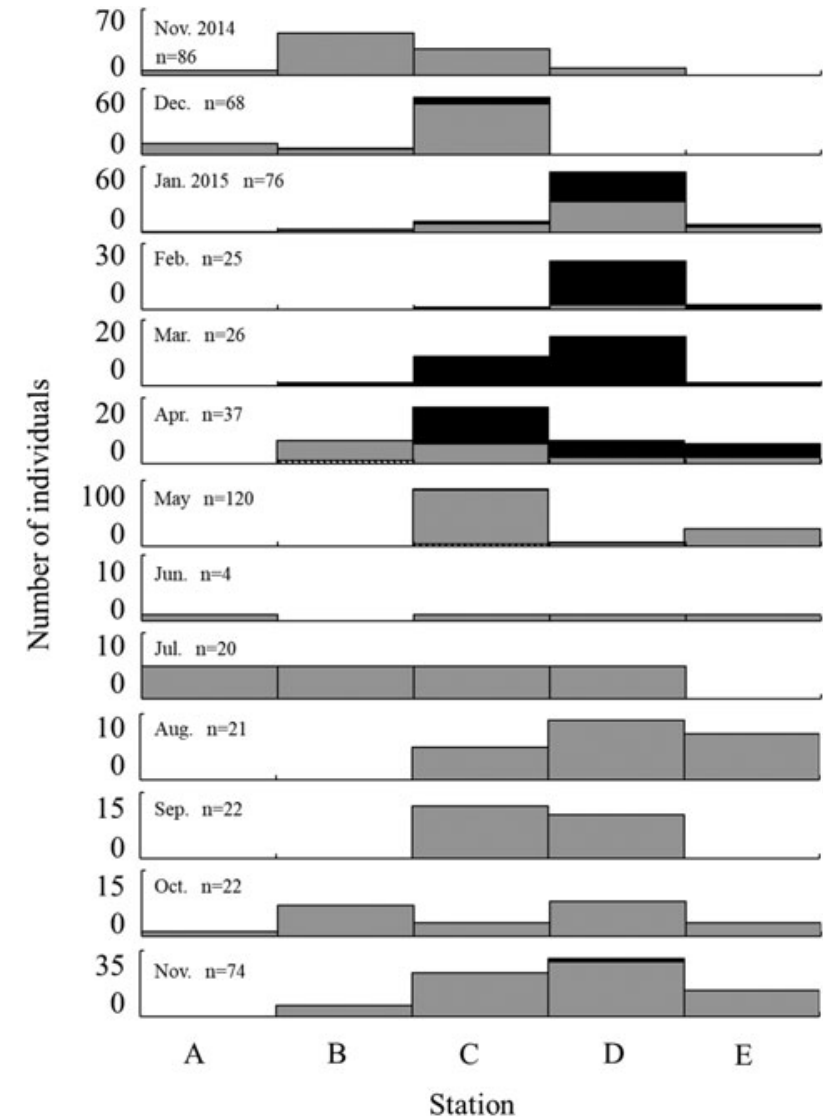

Fig. 7. Monthly changes in standard length of Acanthogobius insularis collected by seine net at each station. Stripe: $\leq 10 \mathrm{~mm}$ SL, grey: 10.1 39.9 mm SL, black: $\geq 40 \mathrm{~mm} \mathrm{SL}$.

in size frequency by new recruits. At the beginning of the rapid growth period, the mean water temperature declined from $24.0^{\circ} \mathrm{C}$ in November to $17.4^{\circ} \mathrm{C}$ in December (Figure 2). The rapid growth of $A$. insularis could be related to decreasing water temperature. Conversely, in mainland Japan, A. flavimanus and A. lactipes mainly grow from spring to autumn, and their growth slows in winter (Takizawa et al., 1994; Zama, 1999). Although most of the Acanthogobius species inhabiting Japan, are distributed in temperate region in East Asia area, A. insularis is the most southern species, distributed only in the sub-tropical area of the Ryukyu Archipelago (Nakabo, 2013). The water temperature of Okinawa-jima Island was higher than that of mainland Japan over the course of a year. For example, the monthly average water temperature ranged from $17.1^{\circ} \mathrm{C}$ in January to $32.6^{\circ} \mathrm{C}$ in July in this study, and from $3.2^{\circ} \mathrm{C}$ in January to $25.5^{\circ} \mathrm{C}$ in August in Miyagi Prefecture, northern Japan in a previous study (Zama, 1999). High water temperature of sub-tropical areas in the summer would not be suitable for A. insularis, which might account for their slow growth in the summer. Furthermore, water temperature in winter in Okinawa-jima Island would be suitable for them, and the decrease in water temperature may promote the initiation of rapid growth.

\section{Reproduction}

The spawning season of $A$. insularis was estimated to occur from January to May, peaking in March and April in the
Okinawa-jima Island based on a combination of monthly changes in GSI values and histological observations of gonadal sections (Figure 4). Shibukawa \& Taki (1996) previously estimated the spawning season of this species through its sexual dimorphism and the occurrence of females with matured eggs in Okinawa-jima Island, when they first described this species. However, this was the first study to estimate the spawning season of $A$. insularis by histological observation. In the present study, it was not clarified whether $A$. insularis is a multiple spawner or not since we did not observe any direct evidences of multiple spawning such as POF by the histological observation. However, it was observed that oocyte development of $A$. insularis was asynchronous in the present study. From such aspects, they might be multiple spawners.

A relationship might exist between the frequency of mature females, the GSI value of females, and mean water temperature. The frequency of mature females and GSI values rapidly increased when the mean water temperature dropped $6.6^{\circ} \mathrm{C}$ from November $\left(24.0^{\circ} \mathrm{C}\right)$ to December $\left(17.4^{\circ} \mathrm{C}\right.$ ) (Figures $\left.2 \& 4\right)$. Then, mature females disappeared in June, when there was a sudden elevation of $7.1^{\circ} \mathrm{C}$ in the mean water temperature from May $\left(24.2^{\circ} \mathrm{C}\right)$ to June $\left(31.3^{\circ} \mathrm{C}\right)$. These results suggest that the maturity of female A. insularis may be related to the low water temperature observed in the winter season. Suzuki et al. (1989) indicated that the maturity of $A$. flavimanus individuals was inhibited by water temperatures above $20^{\circ} \mathrm{C}$, and a low temperature period of $11-14^{\circ} \mathrm{C}$ is needed to progress their maturity in the laboratory. Notably, the spawning season of A. flavimanus starts in winter (Dotsu \& Mito, 1955; Zama, 1999, Table 2). Although little is known about the relationship between the maturity of $A$. hasta and water temperature, one is likely because the spawning season of $A$. hasta occurs during winter from Nagasaki Prefecture in western Japan (February to March: Kuno \& Takita, 1997; Table 2). Nevertheless, A. insularis is the only sub-tropical species within the genus Acanthogobius, in which the spawning season started in winter, the same as with the other Acanthogobius species. Conversely, A. lactipes in Kyusyu in western Japan and Miyagi Prefecture in northern Japan is the only species known to spawn during the summer (May to August in Kyushu: Dotsu, 1959; June to August in Miyagi Prefecture: Zama, 1999; Table 2). The difference between the spawning season of $A$. lactipes and that of congeners might be the result of some competition in the spawning ground and/or timing with other sympatric Acanthogobius species.

\section{Instream distribution}

Monthly quantitative collection using the small seine net showed that $A$. insularis moves upstream, following recruitment on tidal flats in the estuary, and is then widely distributed in the Taiho River. Larger individuals over $40 \mathrm{~mm} \mathrm{SL}$ gathered around stones, which were used as spawning beds in the reproductive season. Yonezawa \& Shinomiya (2016) reported that this species might move to locations containing cobbles during the spawning season in the Amami-oshima Island, Ryukyu Archipelago. However, the results of the present study provide the first quantitative evidence of their movement in the river. Small individuals $(\leq 15 \mathrm{~mm}$ SL) appeared at Station B in April 2015 (Figure 7). From July 2015, the number of mid-sized individuals (16 to 
Table 2. Summary of spawning season of Acanthogobius species from references.

\begin{tabular}{|c|c|c|c|}
\hline Species & Location & Spawning season & Reference \\
\hline \multirow[t]{7}{*}{ Acanthogobius flavimanus } & Miyazaki Pre. in southern Japan & mid-Jan. to Mar. & Dotsu \& Mito (1955) \\
\hline & Goto Islands in western Japan & late-Jan. to late-Mar. & \\
\hline & Kochi Pre. in western Japan & Feb. to Mar. & Miyazaki (1940) \\
\hline & Tokyo Bay in central Japan & late-Feb. to early-May & \\
\hline & Kasumiga-ura, Tokyo & Mar. to Apr. & \\
\hline & Miyagi Pre. in northern Japan & late-Feb. to early-Jun. & Zama (1999) \\
\hline & Hakodate Bay, Hokkaido in northern Japan & Apr. to Jun. & Hoshino et al. (1993) \\
\hline \multirow[t]{2}{*}{ A. lactipes } & Kyusyu in western Japan & May to Aug. & Dotsu (1959) \\
\hline & Miyazaki Pre. in southern Japan & early-Jun. to late-Aug. & Zama (1999) \\
\hline A. hasta & Ariake Sound in Kyusyu & Feb. to Mar. & Kuno \& Takita (1997) \\
\hline A. insularis & Okinawa-jima Island in southern Japan & Jan. to May & This study \\
\hline
\end{tabular}

$39 \mathrm{~mm} \mathrm{SL}$ ) increased in the middle to upper reaches. Finally, adults $(\geq 40 \mathrm{~mm} \mathrm{SL}$ ) appeared in the upper reaches (Stations $\mathrm{C}$ to E) during the spawning season. Several gobies inhabiting brackish, estuary and freshwater areas are known to move upstream according to their growth stage, and change their habitat (Maeda \& Tachihara, 2005; Yokoo et al., 2009, 2012; Kondo et al., 2012; Iida et al., 2013). Acanthogobius insularis might also exhibit this type of movement. Mature-sized individuals occurred in the upper reaches during the spawning season, especially in Station D (Figures 6 \& 7). Acanthogobius insularis females spawn their eggs underneath stones and males care for the egg mass in the nest (Tachihara, 2015; Yonezawa \& Shinomiya, 2016); therefore, a base for a spawning bed, such as stones and shells, is needed for successful spawning. Actually, cobbles of about $15 \mathrm{~cm}$ in diameter were abundant in Station D compared with the other stations (Kunishima et al., unpublished). Therefore, it is quite probable that $A$. insularis individuals moved to Station D, where cobbles were dotted on the pebble substrate, and used the cobbles for their spawning nest.

In this study, the SL of females was higher than that of males. In general, males are larger in species where males guard the nest. In addition, in the congeneric species A. lactipes, the male is larger than the female (Dotsu, 1959; Zama, 1999). During the survey, we were unable to find egg clutches, even during the spawning period, although adult males of $A$. insularis have been reported to take care of egg clutches that are attached to the underside of stones (Tachihara, 2015; Yonezawa \& Shinomiya, 2016). Sex differences in SL might be biased due to the low capture probability of large males guarding their nests under the cobbles.

\section{Life history}

The life history of A. insularis is almost completely described in the present study. The larvae hatch at $3.1 \mathrm{~mm}$ TL, and settle after 25 days (Tachihara, 2015). They are recruited and settle into the estuary as juveniles at $\sim 9.6 \mathrm{~mm}$ SL from April to May. After recruitment, they move upstream to grow. When the water temperature decreases, rapid growth and maturation occur from December to January. During the spawning season between January and May, mature adults ( $\geq 40 \mathrm{~mm} \mathrm{SL}$ ) gather in places containing cobbles for their spawning ground. Females spawn on the underside of stones and males care for the egg mass (Tachihara, 2015; Yonezawa \& Shinomiya,
2016). After spawning, adults complete their annual life cycle and die.

\section{Conservation}

Acanthogobius insularis is ranked as 'vulnerable' in the Red Data Book of Ministry of the Environment of Japan (Tachihara, 2015). Due to its limited distribution, there is an urgent need to conserve the estuarine and brackish areas inhabited by $A$. insularis, which are restricted to the river systems of Amami-oshima and Okinawa-jima Islands of the Ryukyu Archipelago (Shibukawa \& Taki, 1996). Moreover, recently this species has been found to sparsely inhabit the southern part of Okinawa-jima Island (Kunishima et al., 2017). New populations of this species also need to be conserved. Hood (2004) and Inui \& Koyama (2014) suggested there is a need to take measures to conserve brackish areas, considering the effects of direct anthropogenic activities on habitat loss as well as indirect effects such as habitat changes in the surrounding areas.

In this study, low water temperature was shown to be an important factor for the maturity and growth of $A$. insularis. The maturity and growth of fishes are often affected by water temperature, and there is a concern that elevated water temperatures may inhibit fish reproduction by shifting spawning timing (Lehtonen, 1996; Pankhurst \& Munday, 2011). If the water temperature increased as the result of climate change, or due to inflow of warm water discharge, this would threaten $A$. insularis.

Juveniles of this species recruit in tidal flats and estuaries. However, the number of juveniles collected in this study was low, five individuals, even during a recruiting period. Red soil sediments were found to be deposited in lower reaches (Stations A, B), and run-off occurred following heavy rain. O'Connor et al. (2016) highlighted the complex effects of sediment pollution on the ability of larval coral reef fish to find a suitable habitat, affecting their post-settlement performance and recruitment success. Recruitment of $A$. insularis might thus be affected by the disturbance of red soil pollution. After recruitment in tidal flats and estuaries, they moved upstream for growth and gathered in areas containing an abundance of cobbles for spawning during the reproductive season. Thus, A. insularis utilized various habitats from tidal flats to the upper brackish area throughout their life cycle. Considering their life history, sustaining aquatic environments, including tidal flats, estuaries, rivers, and substrate 
for use as an appropriate upstream spawning ground, is fundamental for the conservation of this vulnerable species.

\section{SUPPLEMENTARY MATERIAL}

The supplementary material for this article can be found at https://doi.org/10.1017/Soo25315417002053.

\section{ACKNDWLEDGEMENTS}

We are grateful to the members of the Tachihara Laboratory, University of the Ryukyus for their help during the survey and laboratory works. We also thank Fabienne Ziadi-Künzli (OIST, Okinawa Institute of Science and Technology Graduate University) for proofreading this manuscript and the anonymous reviewers who commented on an early version of the manuscript.

\section{FINANCIAL SUPPDRT}

T.K. was partly supported by Research Fellowships of the Japan Society for the Promotion of Science (JSPS). This study was partly supported by the Sasakawa Scientific Research Grant from The Japan Science Society (Research number: 27-706) and JSPS KAKENHI Grant (JP16J07695) to T.K. All surveys in the present study complied with the current laws of Japan.

\section{REFERENCES}

Able K.W. (2005) A re-examination of fish estuarine dependence: evidence for connectivity between estuarine and ocean habitats. Estuarine, Coastal and Shelf Science 64, 5-17.

Akihito, Sakamoto K., Ikeda Y. and Aizawa M. (2013) Acanthogobius. In Nakabo T. (ed.) Fishes of Japan with pictorial keys to the species, $3 \mathrm{rd}$ edition. Kanagawa, Japan: Tokai University Press. [In Japanese]

Arun A.U. (2005) Impact of artificial structures on biodiversity of estuaries: a case study from Cochin estuary with emphasis on clam beds Applied Ecology and Environmental Research 4, 99-100.

Dotsu Y. (1959) The life history and bionomics of the gobiid fish, Aboma lactipes (Hilgendorf). Bulletin of the Faculity of Fisheries Nagasaki University 8, 196-201. [In Japanese with English abstract]

Dotsu Y. and Mito S. (1955) On the breeding habits, larvae and young of a goby, Acanthogobius flavimanus (Temminck et Schlegel). Japanese Journal of Ichthyology 4, 153-161. [In Japanese with English abstract]

Elliot M. and Dewailly F. (1995) The structure and components of European estuarine fish assemblage. Netherlands Journal of Aquatic Ecology 29, 397-417.

Elliot M., Whitfield A.K., Potter I.C., Blaber S.J.M., Cyrus D.P., Nordlie F.G. and Harrison T.D. (2007) The guild approach to categorizing estuarine fish assemblages: a global review. Fish and Fisheries 8, 241-268.

Eriksson B.K., van der Heide T., van der Koppel J., Piersma T., van der Veer H.W. and Olff H. (2010) Major changes in the ecology of the Wadden Sea: human impacts, ecosystem engineering and sediment dynamics. Ecosystems 13, 752-764.

Froese R. and Pauly D. (2017) FishBase. World Wide Web electronic publication. www.fishbase.org, version (02/2017) (accessed 30 April 2017).
Fujii H. (2001) The present status of tidal flats on the Okinawa Island. Japanese Journal of Benthology 56, 29-31. [In Japanese with English abstract]

Hood W.G. (2004) Indirect environmental effects of dikes on estuarine tidal channels: thinking outside of the dike for habitat restoration and monitoring. Estuaries and Coast 27, 273-282.

Hoshino N., Kinoshita T. and Kanno Y. (1993) Age, growth and ecological characteristics of goby, Acanthogobius flavimanus, in Hakodate Bay, Hokkaido, Japan. Bulletin of the Faculity of Fisheries Hokkaido University 44, 147-157. [In Japanese with English abstract]

Humphries P. and Potter I.C. (1993) Relationship between the habitat and diet of three species of atherinids and three species of gobies in a temperate Australian estuary. Marine Biology 116, 193-204.

Iida M., Watanabe S. and Tsukamoto K. (2013) Riverine life history of the amphidromous goby Sicyopterus japonicus (Gobiidae: Sicydiinae) in the Ota River, Wakayama, Japan. Environmental Biology of Fishes $96,645-660$

Inui R. and Koyama A. (2014) Gobiid fishes inhabiting estuarine tidal flats in Honshu, Shikoku and Kyushu. Japanese Journal of Ichthyology 61, 105-109. [In Japanese]

Kanou K., Koike T. and Kohno H. (2000) Ichthyofauna of tidelands in the inner Tokyo Bay, and its diversity. Japanese Journal of Ichthyology 47, 115-129. [In Japanese with English abstract]

Kitano T., Hatakeyama R., Akiyama N. and Ueno S. (2003) Relationship between annual reproductive cycle of female flat-head goby, Luciogobius guttatus and the seasonal change in water temperature in estuaries along the northern Suruga Bay. Aquaculture Science 51, 41-48. [In Japanese with English abstract]

Kondo M., Maeda K., Yamasaki N. and Tachihara K. (2012) Spawning habitat and early development of Luciogobius ryukyuensis (gobiidae). Environmental Biology of Fishes 95, 291-300.

Kunishima T., Maeda K. and Tachihara K. (2017) Newly discovered habitat of a threatened goby, Acanthogibius insularis (Perciformes: Gobiidae), in southern part of Okinawa-jima Island, Japan. Biogeography 19, 97-103.

Kuno Y. and Takita T. (1997) The growth, maturation and feeding habits of the Gobiid fish Acanthogobius hasta distributed in Ariake Sound, Kyushu, Japan. Fisheries Science 63, 242-248.

Lehtonen H. (1996) Potential effects of global warming on northern European freshwater fish and fisheries. Fisheries Management and Ecology 3, 59-71.

Maeda K. and Tachihara K. (2005) Recruitment of amphidromous sleepers Eleotris acanthopoma, Eleotris melanosoma, and Eleotris fusca into the Teima River, Okinawa Island. Ichthyological Research 52, $325-335$.

Meager J.J., Williamson I. and King C.R. (2005) Factors affecting the distribution, abundance and diversity of fishes of small, soft-substrata tidal pools within Moreton Bay, Australia. Hydrobiologia 537, 71-80.

Miyazaki I. (1940) Studies on the Japanese common goby, Acanthogobius flavimanus (Temminck et Schlegel). Bulletin of the Japanese Society of Scientific Fisheries 9, 159-180. [In Japanese with English abstract]

Nakabo T. (2013) Fishes of Japan with pictorial keys to the species, 3rd edition. Kanagawa, Japan: Tokai University Press.

Nakamura M. (2002) Studies on growth and maturity of the Japanese common goby, Acanthogobius flavimanus. Bulletin of Ibaraki Prefecture Freshwater Fisheries Experimental Station 37, 29-34. [In Japanese]

O'Connor J.J., Lecchini D., Beck H.J., Cadioul G., Lecellier G., Booth D.J. and Nakamura Y. (2016) Sediment pollution impacts sensory ability and performance of settling coral-reef fish. Oecologia 180, 11-21. 
Okazaki D., Yokoo T., Kanou K. and Kohno H. (2012) Seasonal dynamics of fishes in tidepools on tidal mudflats in the Tama River estuary, central Honshu, Japan. Ichthyological Research 59, 63-69.

Okinawa Prefecture (2013) The enforcement of the Okinawa prefecture red soil erosion ordinance. http://www.pref.okinawa.jp/site/kankyo/ hozen/documents/o1kihonkeikaku131213.pdf (accessed 21 February 2018). [In Japanese]

Pankhurst N. and Munday P. (2011) Effects of climate change on fish reproduction and early life history stages. Marine and Freshwater Research 62, 1015-1026.

R Core Team (2013) R: a language and environment for statistical computing. Vienna: R Foundation for Statistical Computing. http://www. R-project.org.

Schneider C.A., Rasband W.S. and Eliceiri K.W. (2012) NIH image to ImageJ: 25 years of image analysis. Nature Methods 9, 671-675.

Shibukawa K. and Taki Y. (1996) A new gobiid fish, Acanthogobius insularis, from the Ryukyu Islands, Japan. Ichthyological Research 43, 79-85.

Suzuki N., Sakurai N. and Sugihara T. (1989) Effect of water temperature on the maturation of the oriental goby Acanthogobius flavimanus. Aquaculture Science 37, 267-274. [In Japanese with English abstract]

Suzuki T., Shibukawa K. and Yano K. (2004) Photography guide to gobioid fishes of Japan. Tokyo: Senou H. (ed) Heibonsha. [In Japanese]

Tachihara K. (2005) Acanthogobius insularis. The threatened wildlife in Okinawa, 2nd edn (Animals) - red data Okinawa. Okinawa: Nature Conservation Division, Department of Cultural and Environmental Affairs, pp. 181-182. [In Japanese]

Tachihara K. (2015) Acanthogobius insularis. Red data book 2014 Threatened wildlife of Japan, volume 4, Pisces - Brackish and fresh water fishes. Tokyo: Gyosei Corporation, pp. 328-329. [In Japanese]

Takizawa K. (1994) Seasonal change in fish communities of the mud flat area at the mouth of the Kutanabe-gawa Brook, Yamaguchi. Journal of the Shimonoseki University of Fisheries 42, 101-108.

Takizawa K., Maruta H., Ikawa M., Nakamura M. and Nakamoto T. (1994) Population structure and maturation of whitelimbed goby
(Acanthogobius lactipes) of a mud flat area at the mouth of the Kutanabe-gawa Brook, Yamaguchi. Journal of the Shimonoseki University of Fisheries 43, 27-33.

UNESCO (1981) Tenth report of the joint panel on oceanographic tables and standards. UNESCO Technical Papers in Marine Science, no. $36,26 \mathrm{pp}$.

Whitfield A.K. (2016) The role of seagrass meadows, mangrove forests, salt marshes and reed beds as nursery areas and food sources for fishes in estuaries. Reviews in Fish Biology and Fisheries 27, 75-110.

Yokoo T., Kanou K., Moteki M., Kohno H., Tongnunui P. and Kurokura H. (2012) Assemblage structures and spatial distributions of small gobioid fishes in a mangrove estuary, southern Thailand. Fisheries Science 78, 237-247.

Yokoo T., Sakamoto T., Kanou K., Moteki M., Kohno H., Tongnunui P. and Kurokura H. (2009) Morphological characters and occurrence patterns of juveniles of two estuarine gobies, Acentrogobius kranjiensis and Acentrogobius malayanus, verified by molecular identification. Journal of Fish Biology 75, 2805-2819.

Yonezawa T. and Shinomiya A. (2016) Acanthogobius insularis. Red data book 2016. The threatened wildlife in Kagoshima prefecture, 2nd edn (Animals). Kagoshima: Environment and Citizens Affairs Department, Kagoshima Prefecture Office (ed) Kagoshima Environmental Research and Service, pp. 96. [In Japanese]

and

Zama A. (1999) Ecological study on the fishes found in Mangoku-ura, Miyagi Prefecture. PhD thesis. Tokyo University of Fisheries, Tokyo, Japan. [In Japanese]

\section{Correspondence should be addressed to:}

T. Kunishima

Graduate School of Engineering and Science, University of the Ryukyus, 1 Senbaru, Nishihara, Okinawa 903-0213, Japan email: taigakunishima@gmail.com 